\title{
EDITORIAL
}

\section{De pandemias, sentimientos y poesía de los cuidados}

\section{About pandemics, feelings and poetry of care}

\section{De pandemias, sentimentos e poesia de cuidados}

\section{José Siles ${ }^{1}$}

${ }^{1}$ Catedrático del departamento de enfermería. Facultad Ciencias de la Salud. Universidad de Alicante. Cómo citar este artículo en edición digital: Siles, J.(2020). De pandemias, sentimientos y enfermería.

Cultura de los Cuidados (Edición digital), 24(56). Recuperado de http://dx.doi.org/10.14198/cuid.2020.56.01

Correspondencia: Departamento de enfermería. Facultad de Ciencias de la Salud. Universidad de Alicante, Alicante. CP 3080

Correo electrónico: jose.siles@ua.es

Recibido:25/03/2020 Aceptado: Invitación editorial

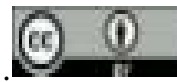

\section{ABSTRACT}

This editorial reflects on the chaos caused by the Covid-19 pandemic, nursing response and the poetry of care.

Keywords: Nursing, poetry of care, pandemic.

\section{RESUMEN}

En esta editorial el autor reflexiona sobre el caos provocado por la pandemia del Covid-19, la respuesta de la enfermería y la poesía de los cuidados.

Palabras clave: enfermería, poesía de los cuidados, pandemia.

\section{RESUMO}

Neste editorial, o autor reflecte sobre o caos causado pela pandemia de Covid-19, a resposta da profissão de enfermagem e a poesia dos cuidados

Palavras-chave: enfermagem, poesía dos cuidados, pandemia.
Planteamiento de la situación: Reacción de las enfermeras ante la muerte en aislamiento

Desde que el misterio alredor de la muerte, hecho difícilmente asumible por el homo sapiens, activara la creatividad del único “animal racional” dando lugar al nacimiento de sistemas de creencias y la construcción de significados que le dieran cierto sentido, todo lo que gira alrededor del fin de la vida está regulado por dogmas variados y antidogmas que, desnudos de ecuaciones despejadoras de incógnitas, igualmente precisan del consuelo de una despedida más o menos coherente con las formas de vida-muerte organizadas culturalmente. 
Los cuidados de enfermería se

ocupan de facilitar mediante cuidados humanizados en ese proceso trascendental de la existencia, esa despedida final entre aquellos que emprenden el último viaje y sus allegados (familiares, amigos, conocidos). Esta despedida es el principio de un antídoto contra el vacío que va a producir ese enorme hueco que deja un ser querido: el duelo.

Las pestes han dejado, a lo largo de diversas épocas (desde la Antigüedad hasta la pandemia de gripe de 1918, pasando por la Edad Media, Renacimiento, etc.) una huella inmemorial sobre aquellas situaciones en las que resulta imposible la despedida tal como está establecida culturalmente. En estos momentos históricos vuelve a producirse la terrible experiencia del desconsuelo en medio de un caos que provoca la ausencia de la despedida final.

Es en este contexto en el que las enfermeras han reaccionado de forma tajante acompañando a las personas que estaban muriendo en la más absoluta soledad. Como sostiene Vigotski (2004) el ser humano se construye a sí mismo enfrentándose a situaciones emocional y estéticamente intensas y complejas demostrando que en las peores situaciones pueden sacar lo mejor de sí mismas (de forma similar al fenómeno de la resiliencia). El papel de los sentimientos en la construcción personal es indisociable del entorno. Katzentbach (2011) en su novela El Psicoanalista, describe esta renuncia al enriquecimiento social, personal $\mathrm{y}$ profesional que experimentan las personas en contextos desfavorables generándose en ellas la frustración que provoca la desconfianza, el miedo y el dolor ante los demás. En el caso de la enfermería y en la actual situación de enfrentamiento apenas sin recursos de protección (Epis) a una pandemia tan explosiva como imprevisible, es evidente que hay datos objetivos para que emerjan sentimientos de este tipo que favorecerían esa renuncia al enriquecimiento personal, sobre todo por el miedo al contagio personal y del entorno más cercano.

Sin duda, las enfermeras están viviendo una situación que genera emociones y sentimientos y que les provoca un recelo (humano y lógico) que es, empero, superado por otro sentimiento: el del deber moral y profesional. El resultado de esta contienda estética y emocional va a repercutir, a pesar del sufrimiento, en su optimización humana y personal, pues el recuerdo imborrable de aquellos momentos “sublimes" (donde se "anundan” el dolor y el amor) en los que “anudaron” su mano con la del paciente en sus últimos instantes es muy posible que les reconforte de por vida congraciándose como integrantes de la especie humana. Tal como sostienen los promotores de \#YoLeCojoLaManoPorTi:

“(...) miles de familiares de los pacientes con coronavirus se les atasca la voz y se les encorseta algo en el pecho cuando piensan que sus padres, sus abuelos o sus hermanos no compartirán los últimos minutos de su vida con ningún calor humano, con ningún apretón que les reconforte en este inesperado viaje(...) (Vilardón, 20020) 
Revista científica de la Asociación de Historia y Antropología de los Cuidados (Universidad de Alicante)

Pero dicho esto, hay que considerar

que es en estas situaciones donde la grandeza y la miseria del ser humano resultan casi imposibles de enmascarar: mientras hay enfermeras, médicos, auxiliares, celadores, limpiadoras que se juegan la vida y la de sus allegados entregándose en cuerpo y alma al noble ejercicio de los cuidados; enfermeras que ofrecen su mano para acompañar en su última travesía a los aislados moribundos, enfermeras que se buscan los medios para que sus pacientes puedan comunicarse con sus familiares a través de un IPad, enfermeras, en definitiva, que orgullosas y alegres aplauden haciendo un pasillo de honor a todos aquellos que van logrando salir del acoso mortal del Covid-19; hay también vecinos que les mandan cartas pidiédoles que se vayan de sus casas porque son un peligro para su comunidad. Mientras en los primeros el deber y la moral prevalecen sobre el miedo transformándolos en seres humanos más humanizados y mejor moldeados como personas, en los segundos el miedo, la aprehensión y el recelo han arrasado con la dignidad transformándolos en la escoria que también y de forma no estrictamente marginal, forma parte de la tribu de sapiens. En este baile desenfrenado de sentimientos categorizados por (Heller, 2004): estéticos (lo bello, lo sublime), morales (el deber, la moral), agradables (satisfacción, orgullo), desagradables (miedo, deber, ira, recelo, odio, culpa, inseguridad), es donde el ser humano, que está anegado por todos ellos, tiene que ir gestionándolos y construyéndose como tal. Ya lo dijo Terencio: "Nada de lo humano me es ajeno" y cuanto más conscientes seamos de esto más controlaremos nuestro proceso de construcción personal gestionando de forma consciente nuestras emociones y sentimientos.

La poesía de los cuidados y la sociopoética como herramientas de gestión de emociones y sentimientos

\section{Poesía de los cuidados}

Son ya varios los autores que han investigado la poesía de los cuidados (Birx, 1994; Holmes and Gregory, 1998, Siles y Solano, 2011, 2016, 2019; Siles, 2015). Para disertar sobre esta temática hay que clarificar conceptos que convergen en su construcción: arte y estética. Sin duda, la enfermería es un "arte" que acontece mediante a interacción entre dos individuos (paciente y profesional) y cuya acción cuidadora (activa por parte del profesional y receptora por parte del paciente), da lugar a una obra artística en cuya producción se involucran aspectos esenciales del ser humano: conocimiento, técnica, intuición y sensibilidad (Siles y Solano, 2011). Mientras el concepto "arte" alude al proceso de producción del cuidado, el de "estética" se refiere a la percepción de los sentimientos que emergen durante esta interacción cuidador-cuidado. "Estética" deriva de dos términos griegos: "aisthetike" que significa percepeción, sensación y "aisthesis" que se refiere a sensibilidad. 
Entre las utilidades de la poesía de los cuidados se pueden destacar:

-Desahogo emocional y estético mediante la expresión y comunicación de sentimientos que funcionan como catarsis y, que de otra forma, quedan enquistados pudiendo causar problemas tan serios como la desmotivación profesional e incluso el burnt out.

-Utilidad en la práctica profesional y personal basada en el potencial de autoconocimiento del yo estético y emocional mediante la gestión consciente de emociones y sentimientos. Este control estético facilita el crecimiento personal, tal como sostiene Whitman en el poema nuclear de Hojas de Hierba, "The song of myself" donde revela el propósito fundamental de su poesía: reconocerse, reencontrarse y crecer construyéndose como persona al compás de los versos mediante los que va armando la nave de su poesía (Siles, 2015). Pero no resulta tan sencillo llegar a la concienciación $\mathrm{y}$ control emocional $\mathrm{y}$ estética, dado que buena parte de nuestros sentimientos funcionan como obnubiladores (vanidad, egoísmo, miedo, recelo, envidia) que nos mantienen alejados de la atención crítica y autocrítica de nuestros actos y sus consecuencias (buen ejemplo tal vez sea la actitud de los vecinos que repudian a los enfermeros de su comunidad...¿¿̇son conscientes de que están dominados por el miedo? Es por ello que la poesía de los cuidados debe ir siempre unida a una base reflexiva en cuyo proceso esté activo el pensamiento crítico y autocrítico (Siles y Solano, 2019).

-La trascendencia de los cuidados. Sin duda, la más importante aportación de la poesía a la enfermería radica en la clarificación de su naturaleza transcendente mediante la revelación de su objeto sujeto: el ser humano. La persona como núcleo, como materia prima con la que trabaja la enfermera para "producir su obra". No hay ningún artista que trabaje con una materia prima tan sumamente frágil, delicada, compleja, única e irrepetible... he ahí su carácter transcendente. Para Watson (2008) la poesía de los cuidados aporta la trasncendencia en forma de verdad. En esta misma línea Birx (1994) la poesía revela la transcendencia de momentos muy intensos en la interacción de los cuidados (lo que para otros autores sería equivalente a los momentos sublimes (Siles y Solano, 2016).

-Por otro lado, siguiendo la categorización de los patrones funcionales de Carper, la poesía de los cuidados es una fuente de conocimiento (Homes y Gregory,1998).

\section{Sociopoética de los cuidados}

A pesar de su gran utilidad, el carácter subjetivo de la poesíala distancia del ámbito científico nopositivista donde sigue imperando el pensamiento y los métodos objetivistas. En los últimos años se han desarrollado estrategias que acercan la poesía a la ciencia (el arte a la objetividad). La sociopoética estudia las formas de expresión que, a través de los sentidos, 
Revista científica de la Asociación de Historia y Antropología de los Cuidados (Universidad de Alicante)

provocan en las personas situaciones de intersubjetividad en la interacción cuidadorcuidado (Siles, 2014).

Para algunos autores, la sociopética ha sido considerada como un puente entre la ciencia y el arte. Para la mayoría de los investigadores, la sociopoética potencia facetas muy específicas y no demasiado trabajadas: la creatividad, la intuición y la sensibilidad (Santos, 2005).

En definitiva, la poesía de los cuidados forma parte de la realidad enfermera (Cody, 1995; Chocarro, 2013). Esta pademia provoca situciones que estamos viviendo colectivamente. Muchas ernfermeras han experimentado momentos muy parecidos de gran intensidad emocional y la poesía de los cuidados y la sociopoética (expresión colectiva de sentimientos provocados por situaciones semejantes) constituyen estrategias de gran calado para reconocerse, seguir creciendo y enriquecerse como personas y enfermeras.

\section{BIBLIOGRAFÍA}

Birx, E. (1994). The poetry of nursing. Clin Nurse Spec. 1994; 8(6):292-93.

Cody, W. (1995). Intersubjectivity: Nursing's contribution to the explication of its postmodern meaning. Nursing Science Quarterly, 8(2), 52-54.

Chocarro, L. (2013). La intersubjetividad y su relevancia en los cuidados de Enfermería

Furman, R. (2004). Using poetry and narrative as qualitative data: Exploring a father's cáncer trought poetry. Family systems \& Health, 22(2), 162-170.
Heller. A. (2004).Teoría de los sentimientos. México: Ediciones Coyoacán; 2004.

Holmes V, Gregory D. Writing poetry: a way of knowing nursing. Journal of Advanced Nursing. 1998; 28: 1191-1194.

Katzenbach, J. (2011). El psicoanalista. Barcelona: Ediciones B

Santos, I. (2005). Sociopoética: un puente para "cuidar - investigar" en enfermería. Index Enferm., 14(50): 35-37

Siles, J. (2014) El humanismo en enfermería a través de la sociopoética y la antropoética. Cultura de los Cuidados,18(38), 9-13

Siles, J. y Solano, C. (2011). Cultural history and aesthetics of nursing care. Rev. LatinoAm. Enfermagem, 5,1096-1105.

Siles, J. \& Solano, C. (2016). Sublimity and beauty A view from nursing aesthetics. Nursing Ethics. Nurs Ethics, 28. doi: 10.1177/0969733014558966

Siles, J. (2015). Walt Whitman, Poesía y Cuidados. Cultura de los Cuidados, 19(43), 12-18.

Siles, J. y Solano, C. (2019). Pensamiento crítico, autoevaluación y estética en la práctica clínica de enfermería. Una aportación desde la antropología educativa. Barcelona: Octaedro.

Vigotsky, L. (2004). Teoría de las emociones. Madrid: Akal.

Vilardón, $\quad$ M. $^{\mathrm{a}} \quad$ (27/03/2020). \#YoLeCojoLaManoPorTi. Recuperado de https://okdiario.com/sociedad/tranquilo-yocojo-mano-ti-iniciativa-enfermerasalcorcon-que-nadie-muera-solo-5367414

Watson, J. (2008). Nursing: The Philosophy and Science of Caring. Colorado: University Press of Colorado. 


\section{Adela Ilamando a su madre en el aire En:}

Siles, J. (2019) La estructura del Aire.

Madrid: Verbum

Aquella noche de luna ausente

el eco de su voz resonaba

a lo largo del oscuro pasillo

ensombreciendo aún más

la antiséptica atmósfera

de aquel hospital

donde el destino dentro de un sobre lacrado

estaba escrito prescribiendo

que la única ceremonia posible

era la despedida final.

Aquella noche de invocación incesante toda su fuerza suplicante

se concentraba en un mismo fin

repitiendo una y otra vez

la misma palabra sin desmayo

llamándola como cuando era niña

anhelante del consuelo y la tierna calidez

de la mujer que la había traído al mundo

...su madre

la madre que volvía a lomos del aire.

Aquella noche de llanto silente

la mano de Adela rasgaba el aire de la habitación

ansiando hallar el último asidero

y buscando el encuentro de la otra mano

para que guiara su postrera travesía

mientras repetía una y otra vez

mamá, mamá, mamá

Aquella noche de luna ausente, invocaciones incesantes

y llantos silentes

Adela se encogía enrollándose sobre sí misma

era un ovillo de escuálida y frágil carne

que sin fuerzas siquiera para respirar

cogiendo un mágico y sorprendente

impulso

estiraba el brazo fuera de la cama

para asir la mano de su madre

muerta sesenta años antes

cuando Adela apenas cumplía los diez

mamá, mamá, mamá.

la madre escuchaba inmersa en el aire.
Aquella noche de luna ausente, invocaciones incesantes

y llantos silentes

Adela halló el consuelo y la tierna calidez en un último cobijo

cuando por fin su mano dejó de agitarse en el aire

al anudarse a aquella otra mano

tendida por una enfermera

que susurró una nana y acarició suave

...su frente sudorosa

la madre le regaló un beso frío de aire.

Nota del autor: Este poema no fue escrito durante la pandemia. Refleja la soledad de la despedida yerma en un hospital andaluz a mediados de los ochenta.

\section{Dedicado a los integrantes del movimiento \#YoLeCojoLaManoPorTi}



Fuente: https://okdiario.com/sociedad/tranquilo-yo-cojomano-ti-iniciativa-enfermeras-alcorcon-que-nadiemuera-solo-5367414 